\title{
Intergeneric hybrids between Saccharomycopsis fibuligera and Yarrowia lipolytica
}

\author{
B. H. Nga, ${ }^{1 *}$ F. D. Abu Bakar, ${ }^{2}$ G. H. Loh, ${ }^{1}$ L. L. ChiU,,${ }^{1}$ S. Harashima, ${ }^{3}$ Y. Oshima ${ }^{3}$ and \\ H. HESLOT ${ }^{4}$
}

'Department of Microbiology, National University of Singapore, Lower Kent Ridge Road, Singapore 0511,
Republic of Singapore
${ }^{2}$ Department of Microbiology, Universiti Kebangsaan Malaysia, Bangi, Malaysia
${ }^{3}$ Department of Biotechnology, Osaka University, Yamada-kami, Suita-shi, Osaka 565, Japan
${ }^{4}$ Laboratoire de Génétique des Microorganismes, Centre de Biotechnologie Agro-Industrielle,
Institut National Agronomique, 78850 Thiverval Grignon, France

(Received 31 July 1991; revised 25 September 1991; accepted 1 October 1991)

\begin{abstract}
Saccharomycopsis fibuligera can utilize starch but not tributyrin as the sole carbon source, whereas Yarrowia lipolytica can utilize tributyrin but not starch. S. fibuligera mutant strain 193 met was crossed to $Y$. lipolytica A hisl to produce hybrids. The intergeneric hybrids were able to utilize both starch and tributyrin as sole carbon source. They were mitotically unstable and gave segregants during prolonged vegetative culture. The majority of these segregants had the phenotype of the $S$. fibuligera parent, with a very low number of genetic recombinants. A more stable hybrid was produced by protoplast fusion between a mutant, ade met, obtained from UV treatment of a Met $^{-}$mitotic segregant of the hybrid 14i and Y. lipolytica B lys5 leu2 ade1 xpr2. Sixteen of the 40 mitotic segregants of this hybrid were recombinants. Furthermore when a haploid mitotic segregant of $S$. fibuligera 193 met, met glu, was crossed to $Y$. lipolytica B leu2 ade1 xpr2 more stable hybrids were also obtained. Eleven of the 35 mitotic segregants of the hybrid SA11 were recombinants. Such high frequencies of recombinant sectors from these hybrids should provide a system to establish genetic mapping analysis for the novel Saccharomycopsis-Yarrowia recombinant strains.
\end{abstract}

\section{Introduction}

The yeasts Saccharomycopsis fibuligera and Yarrowia lipolytica differ from one another in a number of respects (Table 1; Gaillardin et al., 1973; Ogrydziak et al., 1982; Kreger-van Rij, 1984). Their taxonomy has been described by a number of authors (Lodder, 1970; Barnett et al., 1983; Kreger-van Rij, 1984). Gene cloning and transformation systems have been established in $Y$. lipolytica (Davidow et al., 1985, 1987; Gaillardin et al., $1985)$. In the case of $S$. fibuligera, genes for $\alpha$-amylase, glucoamylase, acid protease and $\beta$-glucosidases have been cloned in Saccharomyces cerevisiae (Yamashita et al., 1985a, b, 1986; Itoh et al., 1987; Machida et al., 1988).

\footnotetext{
Author for correspondence. Tel. (65) 7756666; fax (65) 7766872. Abbreviation: OFAGE, orthogonal field alternation gel electrophoresis.
}

Intergeneric hybrids involving either $S$. fibuligera or $Y$. lipolytica with other yeasts have been produced. Provost et al. (1978) found intergeneric hybrids produced by protoplast fusion between Candida tropicalis and $S$. fibuligera to be mitotically unstable, giving rise to the two parental strains in prolonged vegetative culture. Groves \& Oliver (1984) produced intergeneric hybrids between $Y$. lipolytica and Kluyveromyces lactis by protoplast fusion. Although the hybrids had a morphology intermediate between the two parental strains they were also unstable and gave strains which had the phenotype of $Y$. lipolytica.

In the present study, intergeneric hybrids between $S$. fibuligera and $Y$. lipolytica were produced by mass mating and by protoplast fusion. Analysis of genetic segregation among the mitotic sectors of these hybrids was performed to determine the frequency of occurrence of recombinant types. 
Table 1. Differences between Saccharomycopsis fibuligera and Yarrowia lipolytica

\begin{tabular}{|c|c|c|}
\hline & Y. lipolytica & S. fibuligera \\
\hline Vegetative cells & $\begin{array}{l}\text { Pseudohyphae; true } \\
\text { hyphae with central } \\
\text { pore }\end{array}$ & $\begin{array}{l}\text { Pseudohyphae; true } \\
\text { hyphae with septa } \\
\text { having plasmodesmata }\end{array}$ \\
\hline $\begin{array}{l}\text { Fermentation of } \\
\text { sugars }\end{array}$ & $\begin{array}{l}\text { Sugars not } \\
\text { fermented; shows } \\
\text { oxidative metabolism }\end{array}$ & $\begin{array}{l}\text { Slowly ferments sugars; } \\
\text { fermentative }\end{array}$ \\
\hline $\begin{array}{l}\text { Mating system } \\
\text { Genetic systems } \\
\text { Enzymes produced }\end{array}$ & $\begin{array}{l}\text { Heterothallic } \\
\text { Established } \\
\text { Lipase }\end{array}$ & $\begin{array}{l}\text { Homothallic } \\
\text { No information } \\
\text { Glucoamylase } \\
\alpha \text {-Amylase }\end{array}$ \\
\hline
\end{tabular}

\section{Methods}

Strains. S. fibuligera strain 8014 was from the Malaysian Agricultural Research and Development Institute, Serdang, Malaysia. S. fibuligera 193 met was obtained from strain 8014 by UV mutagenesis. Y. lipolytica strains A his1, B leu2 adel xpr2 (reduced ability to produce alkaline protease) and B lys 5 leu 2 adel $x p r 2$ were from the collection of $\mathrm{H}$. Heslot. Saccharomyces cerevisiae SH964 was from the stock of Y. Oshima. A and B are the opposite mating-type alleles of $Y$. lipolytica. The strain met glu (glutamic acid requirement) is a haploid mitotic sector of $S$. fibuligera 193 met.

Media. Complex YEPD medium consisted of $1 \%(w / v)$ peptone, $2 \%$ $(w / v)$ glucose and $1 \%(w / v)$ yeast extract. Difco Yeast Nitrogen Base (without amino acids) (YNB) was used as minimal medium. Supplementation of this medium when required (for classification media) was as follows: $1.5 \%(w / v)$ starch, $2 \%(w / v)$ glucose, $1.5 \%(w / v)$ sodium citrate, $1 \%(\mathrm{v} / \mathrm{v})$ tributyrin, $100 \mathrm{mg} \mathrm{l}^{-1}$ each of methionine, histidine and leucine, $200 \mathrm{mg}$ sodium glutamate $\mathrm{l}^{-1}$ and $50 \mathrm{mg}$ adenine $\mathrm{l}^{-1}$. YPSS medium contained $4 \mathrm{~g}$ yeast extract, $15 \mathrm{~g}$ soluble starch, $1 \mathrm{~g} \mathrm{~K}_{2} \mathrm{HPO}_{4}$ and $0.5 \mathrm{~g} \mathrm{MgSO}_{4} .7 \mathrm{H}_{2} \mathrm{O}$ per litre. YMC medium contained $3 \mathrm{~g}$ malt extract, $5 \mathrm{~g}$ peptone, $3 \mathrm{~g}$ yeast extract and $0.5 \mathrm{~g}$ sodium citrate per litre. When necessary, media were solidified with $2 \%(w / v)$ agar.

Mass mating. S. fibuligera 193 met was crossed with Y. lipolytica A hisl using the method of Gaillardin et al. (1973). Putative hybrids were observed to grow at the meeting points between streaks of cells of the two parent strains on YMC. The hybrids were isolated on YNB supplemented with glucose (YNBG) after two subsequent subcultures on this medium. These were hybrids. The strain met glu was crossed with Y. lipolytica B leu2 ade 1 xpr2 and the hybrids SA6 and SA11 were obtained by subculturing on YNBG.

Protoplast fusion. Strains S. fibuligera 193 met and $Y$. lipolytica B leu 2 adel xpr2 were grown in $40 \mathrm{ml}$ YE medium at $30^{\circ} \mathrm{C}$ for $24 \mathrm{~h}$ with shaking. Then $10 \mathrm{ml}$ portions of these cultures were added to $90 \mathrm{ml} \mathrm{YE}$ medium ( $5 \mathrm{~g}$ yeast extract, $30 \mathrm{~g}$ glucose and $15 \mathrm{~g}$ agar per litre) and grown to exponential phase. The cultures were harvested and washed in sterile distilled water. Cells were then resuspended in $10 \mathrm{ml}$ PTPsorbitol buffer, consisting of $1 \mathrm{M}$-sorbitol, $100 \mathrm{~mm}$-Tris, $5 \mathrm{~mm}$-EDTA and $20 \mathrm{~mm}$-dithiothreitol. Cells of $Y$. lipolytica B leu 2 ade 1 xpr 2 were treated for $5 \mathrm{~min}$, those of $S$. fibuligera $193 \mathrm{met}$ for $15 \mathrm{~min}$. The tubes were kept in ice and the cells were spun down and washed in $8 \mathrm{ml}$ MAP-sorbitol, consisting of $10 \mathrm{~mm}$-2-amino-2-methyl-1,3-propanediol, $0.1 \mathrm{M}$-morpholinoethylene sulphate and $1 \mathrm{M}$-sorbitol, containing $60 \mathrm{mg}$ of Novozym, and incubated at $30^{\circ} \mathrm{C}$ for $30 \mathrm{~min}$. The protoplasts were harvested and washed in MAP-sorbitol containing $5 \%(w / v)$ Ficoll. After centrifugation, the protoplasts were resuspended in $2 \mathrm{ml}$ of an osmotic stabilizing buffer (OSB) consisting of $10 \mathrm{mM}$-Tris/ $\mathrm{HCl}, 10 \mathrm{mM}-$
HEPES, $10 \mathrm{mM}-\mathrm{CaCl}_{2}$ and $1 \mathrm{M}$-sorbitol. Protoplasts from the two strains were mixed in equal volumes, centrifuged, and the pellet was resuspended in $4 \mathrm{ml} 25 \%(\mathrm{v} / \mathrm{v})$ polyethylene glycol in OSB and incubated at $30^{\circ} \mathrm{C}$ for $30 \mathrm{~min}$. Finally an equal volume of OSB was added to the mixture, followed by centrifugation; the pellet was washed once in $2 \mathrm{ml}$ OSB and resuspended in $2 \mathrm{ml}$ OSB. Aliquots from this preparation, and diluted portions thereof, were dispensed into $3.5 \mathrm{ml}$ molten YNBG agar containing $1 \mathrm{M}$-sorbitol (YNBGS) and overlaid onto YNBGS agar plates. The plates were incubated for 7-10 d at $30^{\circ} \mathrm{C}$, when prototrophic fusant hybrids could be observed on the media.

Characterization of the putative hybrid strains. Putative intergeneric hybrids between $S$. fibuligera and $Y$. lipolytica were tested for their ability to grow on YNBG and to utilize starch, tributyrin or citrate as the sole carbon source.

Mitotic sectoring of putative hybrid strains. The aim of this method is to assess the frequency of obtaining mitotic sectors from the hybrid strains grown as single colonies on YPSS for $14 \mathrm{~d}$ at $30^{\circ} \mathrm{C}$. The mitotic sectors were characterized on classification media.

Preparations of gel inserts of yeast chromosomal DNA. The method used was that of De Jonge et al. (1986). Yeasts were grown to exponential phase in YEPD broth at $30^{\circ} \mathrm{C}$ in 2-litre Erlenmeyer flasks. Approximately $10^{10}$ cells were harvested and washed in $20 \mathrm{ml} 0.05 \mathrm{M}$ EDTA, pH 7.5, at room temperature. Following a second centrifugation the cell pellet was resuspended in $20 \mathrm{ml}$ buffer containing $0.05 \mathrm{M}$-EDTA, $10 \mathrm{mM}$-Tris/ $\mathrm{HCl}$ and $10 \mathrm{~mm}$-dithiothreitol and incubated at $30^{\circ} \mathrm{C}$ for $15 \mathrm{~min}$ with gentle shaking. The cells were centrifuged and the pellet resuspended in $20 \mathrm{ml}$ CPE buffer (CPE: $\mathrm{mix}$ $100 \mathrm{ml} 40 \mathrm{~mm}$-citric acid, $120 \mathrm{mM}-\mathrm{Na}_{2} \mathrm{HPO}_{4}, \mathrm{pH} 6.0$, with $4 \mathrm{ml} 0.5 \mathrm{M}$ EDTA, $\mathrm{pH} \mathrm{7.5)}$ and resuspended in $3 \mathrm{ml} \mathrm{CPES} \mathrm{buffer} \mathrm{(CPES:} \mathrm{CPE}$ containing $1.2 \mathrm{M}$-sorbitol and $5 \mathrm{~mm}$-dithiothreitol) and left at $38^{\circ} \mathrm{C}$ for $5 \mathrm{~min}$. To prepare spheroplasts, $40 \mathrm{mg}$ Novozym 234 (Novo Biolabs) was dissolved in $5 \mathrm{ml} \mathrm{1 \% (w/v)} \mathrm{low-melting-point} \mathrm{agarose,} \mathrm{prepared} \mathrm{in}$ CPE buffer, cooled to $38^{\circ} \mathrm{C}$ and immediately mixed with the cell suspension. The mixtures were pipetted into precooled insert plastic moulds and allowed to gel at $0^{\circ} \mathrm{C}$. The agarose blocks were removed from the moulds and kept overnight at $30^{\circ} \mathrm{C}$ in $20 \mathrm{ml} \mathrm{CPE}$ buffer. The CPE buffer was drained off and the inserts were then treated with $0.02 \mathrm{~g}$ proteinase $\mathrm{K}$ in $20 \mathrm{ml}$ NDS.(NDS : $0.5 \mathrm{M}$-EDTA, pH $7.5,10 \mathrm{~mm}$ Tris/ $\mathrm{HCl}$ and $1 \%(\mathrm{w} / \mathrm{v})$ sodium $N$-lauroylsarcosinate) for $48 \mathrm{~h}$ at $50^{\circ} \mathrm{C}$ in a water bath. The agarose blocks were then treated with RNAase $A$ ( $500 \mu \mathrm{g} \mathrm{ml}^{-1}$ in $10 \mathrm{mM}-\mathrm{Tris} / \mathrm{HCl}$ and $15 \mathrm{~mm}-\mathrm{NaCl}$ ) by incubating the inserts for $2 \mathrm{~h}$ at $37^{\circ} \mathrm{C}$ with gentle shaking in $30 \mathrm{ml}$ electrophoresis buffer (TBE: $90 \mathrm{~mm}$-Tris base, $90 \mathrm{~mm}$-boric acid, $2.5 \mathrm{~mm}$-EDTA, pH 8.2) containing $1.5 \mathrm{ml}$ RNAase. RNAase was removed from the inserts by rinsing twice with TBE.

Pulsed-field gel electrophoresis. Electrophoresis (OFAGE) was carried out using an LKB/Pharmacia Pulsaphor apparatus with a hexagonal electrode array. The gel was run in TBE under the following conditions: at $47 \mathrm{~V}$ with a pulse regime of $3600 \mathrm{~s}$ for $96 \mathrm{~h}$, then of $1800 \mathrm{~s}$ for $48 \mathrm{~h}$; and at $92 \mathrm{~V}$ with a pulse regime of $550 \mathrm{~s}$ for $48 \mathrm{~h}$. At the end of the run, the gels were stained with ethidium bromide $\left(0.5 \mu \mathrm{g} \mathrm{ml}^{-1}\right)$ for $1 \mathrm{~h}$ and destained overnight in TBE.

\section{Results and Discussion}

\section{Intergeneric hybrids between S. fibuligera 193 met and Y. lipolytica A hisI}

Prototrophic intergeneric hybrids were produced between $S$. fibuligera 193 met and Y. lipolytica A his 1 by 
Table 2. Classification of the hybrids obtained by mass mating and protoplast fusion

\begin{tabular}{|c|c|c|c|c|}
\hline & \multicolumn{4}{|c|}{ Ability to grow on*: } \\
\hline & $\begin{array}{l}\text { YNB + } \\
\text { citrate }\end{array}$ & $\underset{\text { tributyrin }}{\text { YNB+ }}$ & $\begin{array}{l}\text { YNB + } \\
\text { starch }\end{array}$ & $\begin{array}{l}\text { YNB+ } \\
\text { glucose }\end{array}$ \\
\hline \multicolumn{5}{|l|}{ Parent strains } \\
\hline $193 \mathrm{met}$ & - & - & + & $+b$ \\
\hline A his1 & + & + & - & - \\
\hline \multicolumn{5}{|c|}{ Hybrid strains $\left(\mathrm{Met}^{+} \mathrm{His}^{+}\right.$) } \\
\hline $7 \mathrm{i}$ & + & + & + & + \\
\hline $9 \mathrm{i}$ & + & + & + & + \\
\hline $14 i$ & + & + & + & + \\
\hline $15 \mathrm{i}$ & + & + & + & + \\
\hline \multicolumn{5}{|l|}{ Parent strains } \\
\hline 193 met & - & - & + & $+r$ \\
\hline B leu 2 ade 1 xpr 2 & $+s$ & + & - & - \\
\hline \multicolumn{5}{|c|}{ Hybrid strains $\left(\mathrm{Met}^{+} \mathrm{Leu}^{+} \mathrm{Ade}^{+}\right)$} \\
\hline $\mathbf{F}_{4}$ & - & + & + & + \\
\hline$F_{6}$ & $+\mathrm{s}$ & + & + & + \\
\hline$F_{10}$ & $+s$ & + & + & + \\
\hline$F_{16}$ & - & + & + & + \\
\hline
\end{tabular}

+ or - , ability or inability to grow; $+s$, slow growth; $+b$, basal growth; $+r$, reduced growth.

Table 3. Classification of spontaneous sectors from the hybrid strains obtained from the cross between $S$. fibuligera 193 met and Y. lipolytica 1529 A hisl

\begin{tabular}{|c|c|c|c|c|c|c|}
\hline \multirow{2}{*}{$\begin{array}{c}\text { Hybrid } \\
\text { strain } \\
\left(\mathrm{Met}^{+} \mathrm{His}^{+}\right)\end{array}$} & \multicolumn{5}{|c|}{ No. of sectors with phenotype shown: } & \multirow{2}{*}{$\begin{array}{l}\text { Total } \\
\text { no. of } \\
\text { sectors } \\
\text { tested }\end{array}$} \\
\hline & Met $^{-}$ & $\mathrm{His}^{-}$ & $\mathrm{Met}^{-} \mathrm{Glu}^{-}$ & $\begin{array}{l}\mathrm{Met}^{-} \mathrm{His}^{-} \\
\mathrm{Glu}^{-}\end{array}$ & $\mathrm{Met}^{+} \mathrm{His}^{+}$ & \\
\hline $7 \mathrm{i}$ & 86 & 0 & 2 & 0 & 1 & 89 \\
\hline $9 i$ & 233 & 0 & 2 & 2 & 1 & 238 \\
\hline $14 \mathrm{i}$ & 208 & 0 & 3 & 2 & 0 & 213 \\
\hline \multirow[t]{2}{*}{$15 \mathrm{i}$} & 232 & 0 & 8 & 0 & 0 & 240 \\
\hline & & & & & & 780 \\
\hline
\end{tabular}

mass mating. These strains were able to utilize starch, tributyrin or citrate as the sole carbon source (Table 2). Colonies of the hybrid strains were grown on YPSS for $14 \mathrm{~d}$ at $30^{\circ} \mathrm{C}$, after which mitotic sectors were observed. Each colony gave 12-15 mitotic sectors. A total of 780 mitotic sectors were isolated and characterized on classification media (Table 3). Four were $\mathrm{Met}^{-} \mathrm{His}^{-}$ $\mathrm{Glu}^{-}$and $15 \mathrm{Met}^{-} \mathrm{Glu}^{-}$. This result indicated that most of the mitotic sectors had the phenotype of the parental strain, S. fibuligera 193 met, and only $\mathrm{Met}^{+} \mathrm{His}^{+}$and Met $^{-}$His $^{-}$Glu$^{-}$types were recombinants (unpublished data). When cells of the two $\mathrm{Met}^{-} \mathrm{His}^{-} \mathrm{Glu}^{-}$sectors from the hybrid 14i were streaked onto YE agar, colonies
Table 4. Classification of the sectors from the hybrid strains obtained by protoplast fusion between S. fibuligera 193 met and Y. lipolytica B leu2 adel xpr2

\begin{tabular}{|c|c|c|c|c|c|}
\hline \multirow[b]{2}{*}{$\begin{array}{l}\text { Hybrid } \\
\text { strain }\end{array}$} & \multicolumn{4}{|c|}{ No. of sectors with phenotype shown*: } & \multirow{2}{*}{$\begin{array}{l}\text { Total } \\
\text { no. of } \\
\text { sectors } \\
\text { tested }\end{array}$} \\
\hline & $\begin{array}{c}\mathrm{Met}^{+} \mathrm{Leu}^{+} \\
\mathrm{Ade}^{+}\end{array}$ & Met $^{-}$ & $\mathrm{Met}^{-} \mathrm{Glu}^{-}$ & $\begin{array}{l}\mathrm{Met}^{-} \mathrm{Glu}^{-} \\
\text {Ade }^{-} \mathrm{Leu}^{-}\end{array}$ & \\
\hline $\begin{array}{l}F_{4} \\
F_{4} \\
F_{10} \\
F_{16}\end{array}$ & $\begin{array}{l}0 \\
1 \\
0 \\
1\end{array}$ & $\begin{array}{r}76 \\
170 \\
72 \\
74\end{array}$ & $\begin{array}{l}3 \\
1 \\
2 \\
0\end{array}$ & $\begin{array}{l}1 \\
0 \\
1 \\
0\end{array}$ & $\begin{array}{r}80 \\
172 \\
75 \\
75 \\
\end{array}$ \\
\hline & & & & & $\overline{402}$ \\
\hline
\end{tabular}

- None of the Glu+ sectors showed requirements for leucine or adenine.

which grew were $\mathrm{Met}^{-} \mathrm{Glu}^{-}$and $\mathrm{Met}^{-} \mathrm{His}^{-} \mathrm{Glu}^{-}$. These strains were mitotically stable and are presumed to be haploids or stable aneuploids. This result may be taken to indicate that the mechanism of sectoring is mitotic nondisjunction.

The occurrence of sectors with a $\mathrm{Met}^{-} \mathrm{Glu}^{-}$phenotype was not expected. In order to ascertain the origin of these, a test for sectoring was carried out for $S$. fibuligera 193 met. Seven out of 240 mitotic sectors were $\mathrm{Met}^{-} \mathrm{Glu}^{-}$

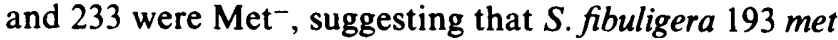
may, indeed, be a naturally occurring diploid heterozygous for $G L U / g l u$ (Abu Bakar, 1990).

\section{Intergeneric hybrids between S. fibuligera 193 met and $Y$. lipolytica B leu2 ade1 xpr2}

A corresponding set of intergeneric hybrids between $S$. fibuligera 193 met and $Y$. lipolytica B leu2 ade 1 xpr 2 was produced by protoplast fusion. The characteristics of these hybrids are given in Table 2 . When colonies of the hybrid strains were grown on YPSS for $14 \mathrm{~d}$ at $30^{\circ} \mathrm{C}, 402$ mitotic sectors were obtained and characterized (Table 4). Two recombinant sectors were obtained. The sectors were predominantly of the phenotype $\mathrm{Met}^{-}$. $\mathrm{Met}^{-} \mathrm{Glu}^{-}$ $\mathrm{Ade}^{-} \mathrm{Leu}^{-}$recombinants are mitotically stable and are presumed to be haploids or stable aneuploids.

Intergeneric hybrids between a mutant, ade met, of a $\mathrm{Met}^{-}$mitotic segregant of the hybrid $14 \mathrm{i}$, and $Y$. lipolytica B lys5 leu2 ade1 xpr2

A Met ${ }^{-}$haploid mitotic segregant of the hybrid 14i was mutagenized by UV treatment to give a mutant, ade met. A hybrid, 20.1, was produced by protoplast fusion between ade met and Y. lipolytica B lys5 leu2 ade1 xpr2. This hybrid utilized starch, tributyrin or citrate as the 
Table 5. Classification of spontaneous sectors from the hybrid 20.1

\begin{tabular}{ccc}
\hline \hline Type & Phenotype & No. of sectors \\
\hline 1 & Ade $^{-}$Met $^{-}$Leu$^{-}$Lys $^{+}$ & 4 \\
2 & Ade $^{-}$Met $^{+}$Leu $^{+}$Lys $^{-}$ & 1 \\
3 & Ade $^{-}$Met $^{+}$Leu $^{+}$Lys $^{+}$ & 4 \\
4 & Ade $^{-}$Met $^{-}$Leu$^{-}$Lys $^{-}$ & 1 \\
5 & Ade $^{-}$Met $^{-}$Leu $^{+}$Lys $^{-}$ & 1 \\
6 & Ade $^{-}$Met $^{-}$Leu $^{-}$Lys $^{-}$ & 5 \\
7 & Ade $^{-}$Met $^{-}$Leu $^{+}$Lys $^{+}$ & 24 \\
\hline
\end{tabular}

sole carbon source. It was unable to grow on media not supplemented with adenine, suggesting that ade of the strain ade met is allelic to ade1 of $Y$. lipolytica. When colonies of the hybrid were cultivated on YPSS for $14 \mathrm{~d}$ at $30^{\circ} \mathrm{C}$, mitotic sectors were obtained at a frequency of 0.7 per colony. Sixteen of the 40 sectors were recombinants (types 1-6; Table 5).

The five type 6 sectors were not able to grow on media supplemented with all the requirements of the parent strains but grew when glutamate was added. When further classified on appropriate media, two were $\mathrm{Leu}^{+}$ Lys $^{+}$, one $\mathrm{Leu}^{-} \mathrm{Lys}^{+}$, and two $\mathrm{Leu}^{-} \mathrm{Lys}^{-}$. These results suggest that the ade met parent of the hybrid may indeed be an aneuploid heterozygous for GLU/glu.

Intergeneric hybrid between a mitotic segregant of $S$. fibuligera 193 met and Y. lipolytica B leu2 ade1 xpr2

A haploid strain met glu which is a mitotic segregant of $S$. fibuligera 193 met was crossed to $Y$. lipolytica B leu 2 ade 1 $x p r 2$ to produce prototrophic hybrids SA6 and SA11. Both the hybrids utilized starch, tributyrin or citrate as the sole carbon source. When colonies of the hybrids were grown on YPSS for $14 \mathrm{~d}$ at $30^{\circ} \mathrm{C}$, mitotic sectors were obtained at a frequency of 0.8 to 1.44 per colony. Twenty-six mitotic sectors from SA11 were characterized as follows: 14 were $\mathrm{Met}^{-}$, two $\mathrm{Met}^{-} \mathrm{Leu}^{-}$, one $\mathrm{Met}^{-}$ $\mathrm{Glu}^{-}$, and nine contained a mixed population of cells of $\mathrm{Met}^{-}$and $\mathrm{Met}^{-} \mathrm{Leu}^{-}$types. In this case therefore 11 out of 35 mitotic segregants of SA11 were recombinants. This result also suggests that $\mathrm{Met}^{-}$segregants are likely to be the progenitors of $\mathrm{Met}^{-} \mathrm{Leu}^{-}$types. Mitotic nondisjunction is probably the underlying mechanism for the change from $\mathrm{Met}^{-}$to $\mathrm{Met}^{-} \mathrm{Leu}^{-}$. $\mathrm{Met}^{-} \mathrm{Leu}^{-}$recombinants are mitotically stable and are presumed to be haploids or stable aneuploids. Furthermore when four of the $14 \mathrm{Met}^{-}$segregants from SA11 were grown on YPSS at $30^{\circ} \mathrm{C}$ for $14 \mathrm{~d}$, three of them gave $\mathrm{Met}^{-}$mitotic sectors at different frequencies and were putative aneuploids whilst the other, which did not give sectors, was

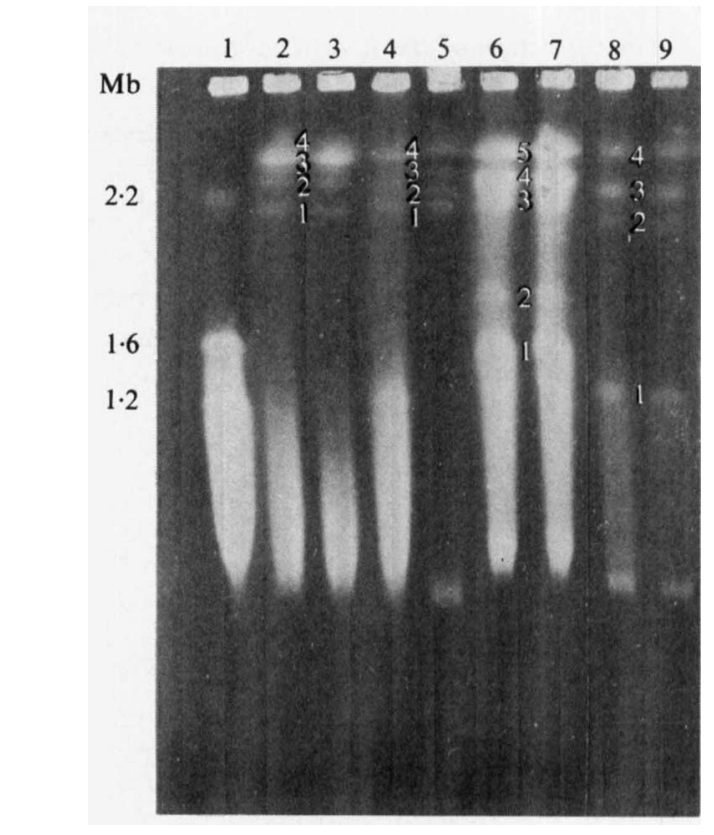

Fig. 1. DNA bands of yeast strains on OFAGE. Lanes: 1, Saccharomyces cerevisiae SH964; 2 and 3, Y. lipolytica A his I; 4 and 5, $Y$. lipolytica B leu2 ade 1 xpr2; 6 and 7, S. fibuligera 193 met; 8, mitotic segregants of the intergeneric hybrid $9 i ; 9$, mitotic segregants of the intergeneric hybrid $14 \mathrm{i}$.

presumably a haploid (G. H. Loh, unpublished data). The three strains that gave sectors differed from the fourth strain in having a reduced growth rate.

The observation that the intergeneric hybrids between $S$. fibuligera 193 met and strains of $Y$. lipolytica were more unstable than the other hybrids was not unexpected as these hybrids were constituted from $S$. fibuligera and $Y$. lipolytica strains which have different karyotypes (Fig. 1). Y. lipolytica strains have four bands (1-4) on OFAGE, $S$. fibuligera has five bands (1-5), and the hybrids between S. fibuligera 193 met and Y. lipolytica A his 1 have four bands. In earlier studies, De Jonge et al. (1986) reported that the OFAGE banding pattern for Saccharomycopsis lipolytica showed one band; Johnston et al. (1988) observed three bands for S. fibuligera in field inversion gel electrophoresis studies on chromosomal DNAs of yeast strains. Bands 1, 2 and 4 of $Y$. lipolytica seem to correspond to bands 3, 4 and 5 of $S$. fibuligera. The intergeneric hybrids $14 \mathrm{i}$ and $9 \mathrm{i}$ have four bands (not shown in Fig. 1) which appear to be similar to those of some of their mitotic segregants. Band 4 of the intergeneric hybrids seems to correspond to bands 4 and 5 of $Y$. lipolytica and S. fibuligera, respectively. Bands 1, 2 and 3 do not correspond to those of either of the parental strains. We take these results to suggest that intergeneric hybrids were indeed produced between $Y$. lipolytica and $S$. fibuligera in our studies. 
The high frequency of occurrence of $\mathrm{Met}^{-}$mitotic sectors in all the intergeneric hybrids seems to suggest a high fidelity of replication of the chromosomes of the $S$. fibuligera parent strain followed by the segregation of a complete set of these chromosomes in cell division in mitosis. The hybrid 20.1 gave $24 \mathrm{Ade}^{-} \mathrm{Met}^{-}$sectors out of 40 . In the case of SA11, 23 out of 35 mitotic segregants were Met $^{-}$. Both these results indicate a significant decrease in frequency of $\mathrm{Met}^{-}$segregants when compared with those described above.

Provost et al. (1978) reported that Candida tropicalis-S. fibuligera hybrids from protoplast fusion were unstable. In prolonged culture the hybrids gave the two parental strains. The authors suggested that the hybrids consist of the genome of one parental strain with a few chromosomes of the other. In another study, Groves \& Oliver (1984) showed that intergeneric hybrids between $Y$. lipolytica and Kluyveromyces lactis had a colonial morphology intermediate between those of the two parental strains. They suggested that the cells of the hybrids gave cells that contained only the genome of $Y$. lipolytica in subsequent mitotic divisions. In both these studies the intergeneric hybrids had a strong tendency to give segregants of one or both parental types in mitotic divisions. An important difference between the results of these previous studies and our present work is that no genetic recombinants were obtained from the mitotic segregants of their intergeneric hybrids.

Our finding that the hybrids 20.1 and SAll gave a relatively high frequency of genetic recombinants in mitotic sectoring may, indeed, provide a significant tool to facilitate development of genetic systems for $S$. fibuligera and for Saccharomycopsis-Yarrowia recombinants. This is especially important because there is no available information on the genetics of $S$. fibuligera; this line of study is at present being investigated in our laboratory.

The isolation of recombinant mitotic sectors such as met glu leu 2 ade 1 and met leu 2 from the intergeneric hybrids $S$. fibuligera $193 \mathrm{met} / Y$. lipolytica B leu 2 ade 1 xpr 2 and met glu/B leu 2 adel $x p r 2$, respectively, is important. We believe that such strains may be used as recipients to establish a transformation system in SaccharomycopsisYarrowia recombinants using the YEp LEU2 cloning vectors.

Some recombinants obtained may prove to be useful in industrial processes based on substrates such as tapioca and sago starch which are available in abundance in the countries of South-East Asia. S. fibuligera can utilize starch but not citrate. We obtained $\mathrm{Met}^{-}$mitotic segregants from SA11 that are able to utilize starch and citrate. As far as we are aware this is the first report of the isolation of such Saccharomycopsis-Yarrowia recombinants.
This work was supported by a grant from the Research and Development Assistance Scheme of the National Science and Technology Board of Singapore. A National University of Singapore Research Grant support, RP 900367, is gratefully acknowledged. We are grateful to Ms Siti Maryam Masnor for help in the preparation of the manuscript.

\section{References}

ABU BaKaR, F. D. (1990). Studies on the intergeneric hybrids between Yarrowia lipolytica and Saccharomycopsis fibuligera. MSc thesis, National University of Singapore, Singapore.

Barnett, J. A., PAYNe, R. W. \& Yarrow, D. (1983). Yeasts: Characteristics and Identification. Cambridge: Cambridge University Press.

Davidow, L. S., Apostolakos, D., O’Donnell, M. M., Proctor, A. R., Ogrydziak, D., Wing, R. A., Stasko, I. \& De ZeEUW, J. R. (1985). Intergrative transformation of the yeast Yarrowia lipolytica. Current Genetics 10, 39-48.

Davidow, L. S., O'Donnell, M. D., Kacmarek, F. S., Pereira, D. A., De Zeeuw, J. R. \& Franke, A. E. (1987). Cloning and sequencing of the alkaline extracellular protease gene of Yarrowia lipolytica. Journal of Bacteriology 169, 4621-4629.

De Jonge, P., De Jonge, C. M., Meijers, R., De Steensma, H. Y. \& SCHEFFERS, W. A. (1986). Orthogonal-field-alternation gel electrophoresis banding patterns of DNA from yeasts. Yeast 2, 193-204.

Gaillardin, C. M., Charoy, V. \& Heslot, H. (1973). A study of copulation, sporulation and meiotic segregation in Candida lipolytica. Archives of Microbiology 92, 69-83.

Gaillardin, C. M., Ribet, A. M. \& Heslot, H. (1985). Intergrative transformation of the yeast Yarrowia lipolytica. Current Genetics 10, 49-58.

Groves, D. P. \& OLIVER, S. G. (1984). Formation of intergeneric hybrids of Yarrowia and Kluyveromyces species. Current Genetics 8 , 49-55.

Itoh, T., Ohtsuki, I., Yamashita, I. \& FukUi, S. (1987). Nucleotide sequence of the glucoamylase gene GLUI in the yeast Saccharomycopsis fibuligera. Journal of Bacteriology 169, 4171-4176.

Johnston, J. R., Contopoulou, C. R. \& Mortimer, R. K. (1988). Karyotyping of yeast strains of several genera by field inversion gel electrophoresis. Yeast 4, 191-198.

Kreger-van RiJ, N. J. W. (1984). The Yeasts. A Taxonomic Study, 3rd edn. Amsterdam: Elsevier Science Publishers.

LODDER, J. (1970). The Yeasts: a Taxonomic Study, 2nd edn. Amsterdam: North Holland.

MAChida, M., OHTSUKI, I., FukUi, S. \& Yamashita, I. (1988). Nucleotide sequences of Saccharomycopsis fibuligera genes for extracellular $\beta$-glucosidase as expressed in Saccharomyces cerevisiae. Applied and Environmental Microbiology 54, 3147-3155.

OGRYDZiaK, D. M., BASSEL, J. \& MoRTIMER, R. (1982). Development of the genetic map of the yeast Yarrowia lipolytica. Molecular and General Genetics 188, 179-183.

Provost, A., Bourguignon, C., Fournier, P., Ribet, A. M. \& HesLOT, H. (1978). Intergeneric hybridisation of yeasts through protoplast fusion. FEMS Microbiology Letters 3, 309-312.

YAMAShITA, I., ITOH, T. \& FUKUI, S. (1985a). Cloning and expression of the Saccharomycopsis fibuligera $\alpha$-amylase gene in Saccharomyces cerevisiae. Agricultural and Bioloical Chemistry 49, 3089-3091.

YAMASHITA, I., ITOH, T. \& FUXUI, S. (1985b). Cloning and expression of the Saccharomycopsis fibuligera glucoamylase gene in Saccharomyces cerevisiae. Applied Microbiology and Biotechnology 23, 130-133.

Yamashita, I., Hirata, D., Machida, M. \& FukUi, S. (1986). Cloning and expression in Saccharomyces cerevisiae of the secretable acid protease gene from Saccharomycopsis fibuligera. Agricultural and Biological Chemistry 50, 109-113. 